\title{
Development of finite element models of gas forming process of Ti alloys structures
}

\author{
K. J. Savinkova, Ya.A. Sobolev \\ Department of Material Forming and Additive Technologies, Federal State Budgetary Educational \\ Institution of Higher Education "Moscow Polytechnic University", Moscow, Russia
}

\begin{abstract}
The use of combined technology of gas forming and solidphase pressure bonding for manufacturing large-diameter torus billets with diameter up to $1500 \mathrm{~mm}$, wall thickness up to $8 \mathrm{~mm}$, and diameter in crosssection up to $400 \mathrm{~mm}$ from titanium alloys for manufacturing of pipeline bends of desired size is shown. The technologymaes it possible to reduce production costs by increasing the productivity of the manufacturing process and applying new design and technological solutions. The possibility of using the SIMULIA Abaqus software package for modeling gas forming of titanium alloys in superplasticityconditions with nonuniform heating of the billets is considered. The method of combined thermo mechanical analysis (COUPLED TEMP-DISPLACEMENT) with inclusion of the creep effect was used.
\end{abstract}

\section{$1 \quad$ Introduction}

The widespread use of titanium alloys in mineral enrichment processes requires the improvement of the technology of manufacturing equipment and spare parts from this expensive material. Kilometers of pipes of the circulation system of technological solutions made of titanium alloys connect processing plants and facilities for the production of nickel, copper, and other metals. A promising technology for the production of titanium products is gas-forming in super plasticity conditions combined with pressure joining in the solid phase[1].It allows to reduce the cost of products not only by increasing the productivity of the manufacturing process but also by using a new design and technological solutions. Elements of titanium pipelines, bends, and transitions can be obtained by cutting into dimensional parts of formed billets of the tor type. The technology is progressive, eliminating numerous operations of hot stamping, straightening, welding. High plastic properties of titanium alloys are implemented under conditions of superplasticity. The technology of the process of obtaining parts is shown below, Figure 1.

Titanium sheet billets 1, 2 in the form of a disk and the gas inlet 3 are placed in the lower half-mould 4 of the die tooling, installed on the table 5 of the press inside the heater 6 . The billets are centered on the outcrop on the lower half-mould with diameter $d$ throughthecentral hole. The gas inlet 3 is placed in a special cavity of the half-mould, which provides an unobstructed closing of the billets, the die, and a sealed gas supply. The upper half-mould 7 is fixed on the press slide 8. Moving down, the upper half-mould seals the heated billets along the outer and inner diameters and the gas inlet. The inner contour of the 
die assembly corresponds to the shape of the torus stamping. Heating and pressure of the press intensify the processes of plastic deformation along the perimeter of the billets, which ensures their reliable joining and tightness. By creating gas pressure in the inner cavity of the billets, the billets are formed into the cavity of the lower and upper half-moulds according to a certain law. At the end of the process, the die opens, the part is pre-cooled and removed from the die.

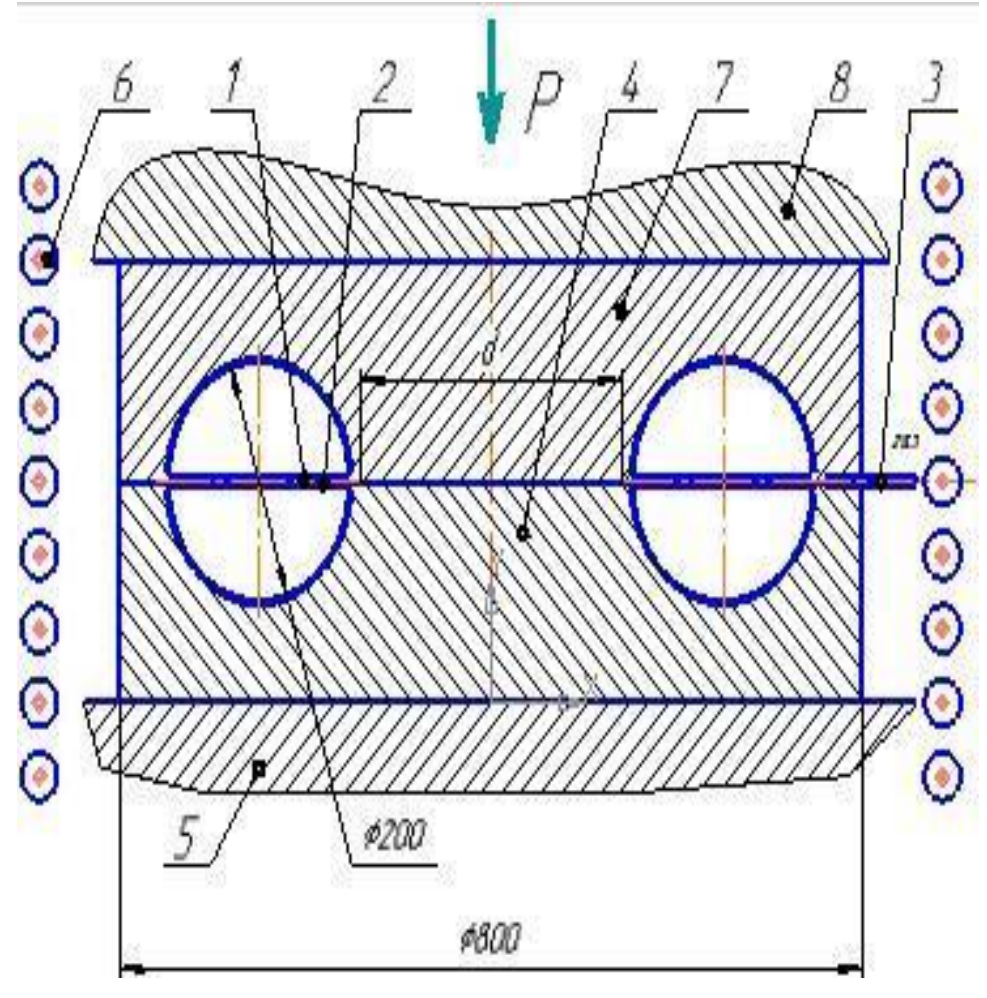

Fig. 1. Die tooling for obtaining torus stamping.

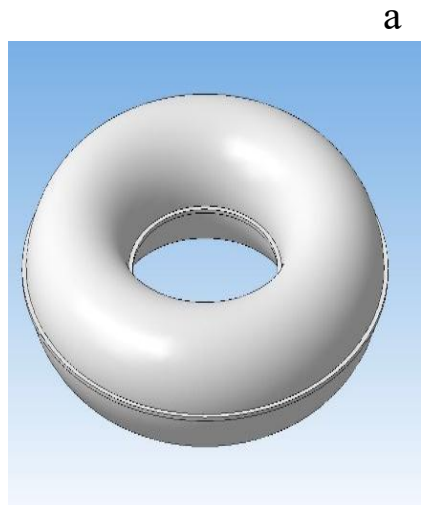

a

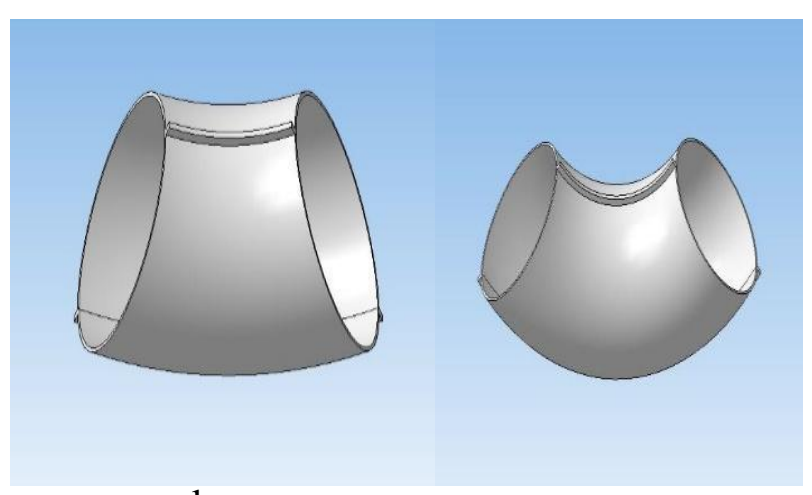

b c

Fig. 2. The billet of type of tor from the sheet $\mathrm{Ti}(\mathrm{a})$, bend $45^{\circ}$ (b), bend $90^{\circ}$ (c). 
Bends of the desired size are obtained by subsequent cutting, Figures $2 b, 2 c$. The technology is promising for bends with a diameter of $50 . .250 \mathrm{~mm}$.

\section{Experiments}

Calculation of the forming parameters is a complex task. Stability of deformation is ensured by temperature-rate conditions determined by heating and change of gas pressure over time. In the case of free-forming sheet billets, the metal thickness deformation depends on the conditions at a particular point: temperature, deformation rate, metal properties, etc. This leads to a significant difference in the thickness of the metal of the resulting stamping. To regulate the deformation on the billet, various methods are used: varying thickness of the original billet, reverse moulding, structure preparation, and other methods [2]. This paper proposes a method of regulation by creating a variable temperature field of the billet, allowing you to control the temperature and speed parameters of metal deformation. A variable temperature field is created when the tooling and billet are heated by adjusting the heater temperature by zone. The calculation technique was developed for moulding spherical parts as the easiest method for moulding. SIMULIA Abaquswas chosen as the main finite element complex for modeling. Foreign authors, such as[3-6], as well as native authors[7], use this software product for modeling the gas-forming of titanium alloys. The tasks of this study include: selection of the problem size and element type for modeling gas forming of titanium hemisphere of VT6 alloy; selection of the solution procedure for modeling the process under both in isothermal and non-uniform conditions of billet heating; evaluation of applicability of rheological models the material available in Abaqus/Standard; evaluation of capabilities of the built-in algorithm for pressure control.

As a model problem, we considered the gas-forming of a of $287 \mathrm{~mm}$ radius hemisphere from a $3.6 \mathrm{~mm}$ thick and $750 \mathrm{~mm}$ diameter circular billet made of VT6 alloy at $\mathrm{f} 900 \mathrm{C}$. During the forming process, it was necessary to maintain the deformation rate in the range of $3 \times 10^{-4}-5 \times 10^{-4} \mathrm{~s}^{-1}$, ensuring high plastic properties of the material-elongation over $1000 \%$. 


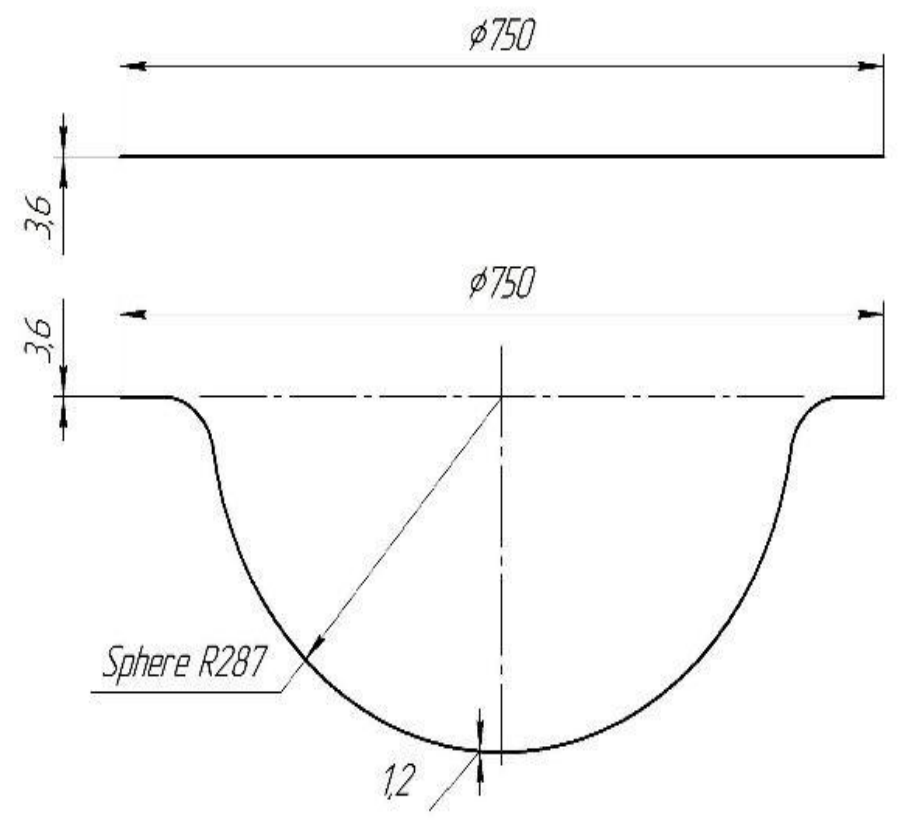

Fig. 3. The billet and the formed hemisphere.

As a rheological model, we used the Norton-Hoff power dependence (1) built into Abaqus/Standard, which allowed to describe short-term creep processes in the form

$$
\dot{\varepsilon}=B \sigma^{n},
$$

Where ćis the strain rate, $B$ is the material constant, $\boldsymbol{\sigma}$ is the equivalent stress, $n$ is the power factor, the inverse of the speed sensitivity coefficient.

Most modern technological processes that use the effect of superplasticityare carried out under isothermal conditions. One of the challenges in developing such processes is choosing the optimal working pressure profile in the gas-forming unitthatensures a constant rate of deformation of the billet. Mathematical modeling is an effective tool for developing an appropriate pressure profile. Abaqus/Standard has a built-in pressure control algorithm that controls the deformation rate in a selected area of the billet or overthe entire billet and, accordingly, reduces the applied pressure to the billet when the maximum set strain rate is exceeded or increases it if the deformation rate is low. We used this built-in algorithm to study its stability and effectiveness. At the same time, the deformation rate was monitored only in the center of the billet, since in isothermal gas forming of hemispheres, the maximum deformation rate usually develops here. The target deformation rate was set at $5 \times 10^{-4} \mathrm{~s}^{-1}$. 


\section{Results and discussion}

Based on the results of modeling the process of gas-formation of a hemisphere with a radius of $287 \mathrm{~mm}$, a hemisphere was formed from a sheet billet $3.6 \mathrm{~mm}$ thick at the SDDS-1 installation [8]. The calculated geometric parameters are shown in Table 1.

Comparison of the calculation results and the actual thickness obtained shows a satisfactory convergence with the difference of $5-7 \%$.

Table 1. The results of modeling.

\begin{tabular}{ccc}
\hline Result & $\begin{array}{c}\text { 3D-model, shell element, } \\
\text { the built-in algorithm of } \\
\text { pressure control }\end{array}$ & $\begin{array}{c}\text { 2D-model, nodal } \\
\text { axisymmetric element, the } \\
\text { built-in algorithm of } \\
\text { pressure control }\end{array}$ \\
\hline $\begin{array}{c}\text { The thickness in the pole } \\
\text { Thickness at the radius on } \\
\text { the mould }\end{array}$ & $1.39 \mathrm{~mm}$ & $1.35 \mathrm{~mm}$ \\
$2.66 \mathrm{~mm}$ \\
The thinning in the pole & $2.77 \mathrm{~mm}$ & $63 \%$ \\
The thinning at the radius & $61 \%$ & $26 \%$ \\
The polythickness (the & $23 \%$ & $1.31 \mathrm{~mm}$ \\
thickness at the radius-the & $1.38 \mathrm{~mm}$ & \\
thickness in the pole) & & \\
\hline
\end{tabular}

Actual measurements of the thickness of the hemisphere are shown in Figure 4. 


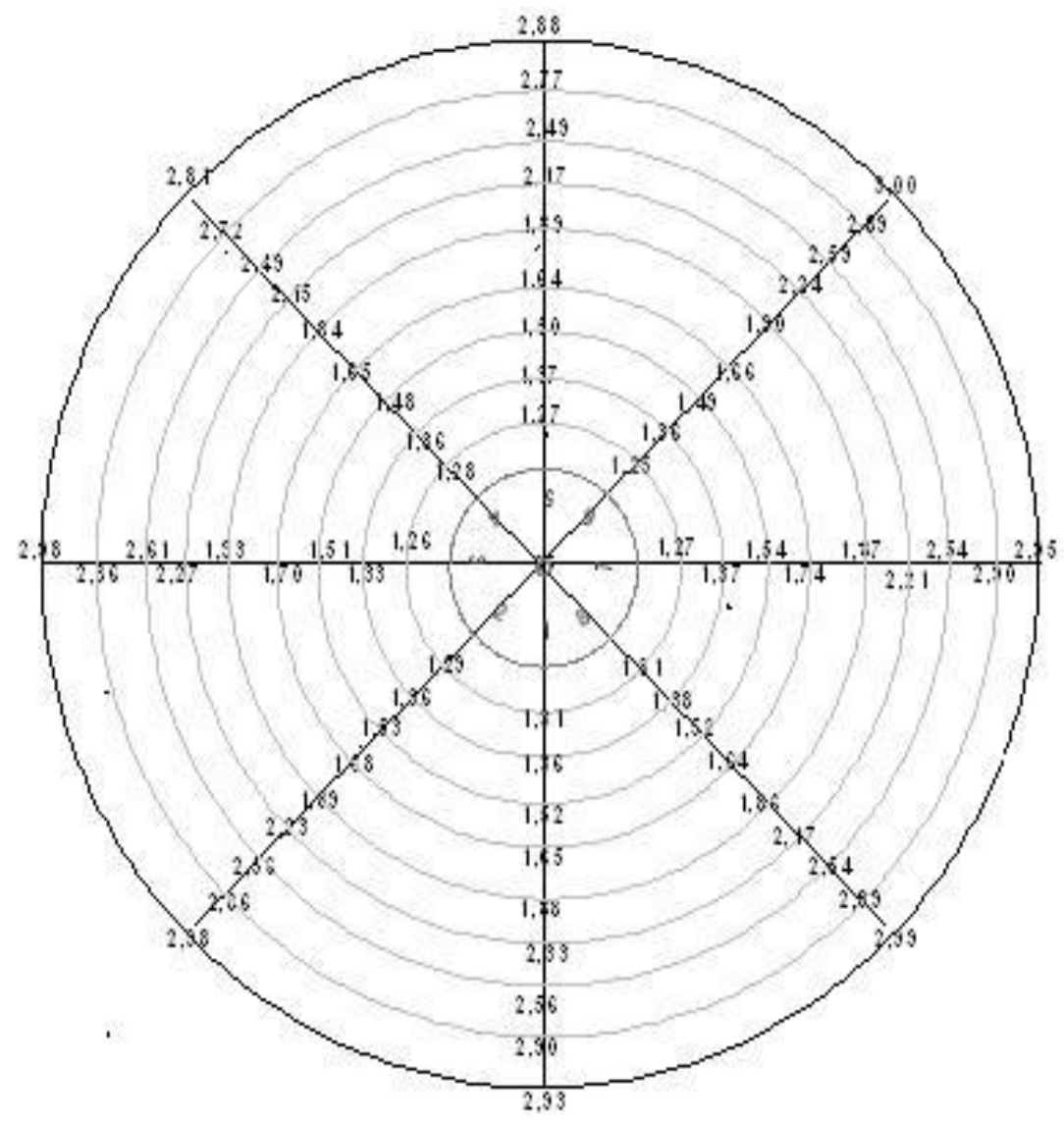

Fig. 4.Measuringsof the metal thickness of the formed hemisphere with $287 \mathrm{~mm}$ radius. The initial thickness of the billet with $750 \mathrm{~mm}$ diameters $3.6 \mathrm{~mm}$.

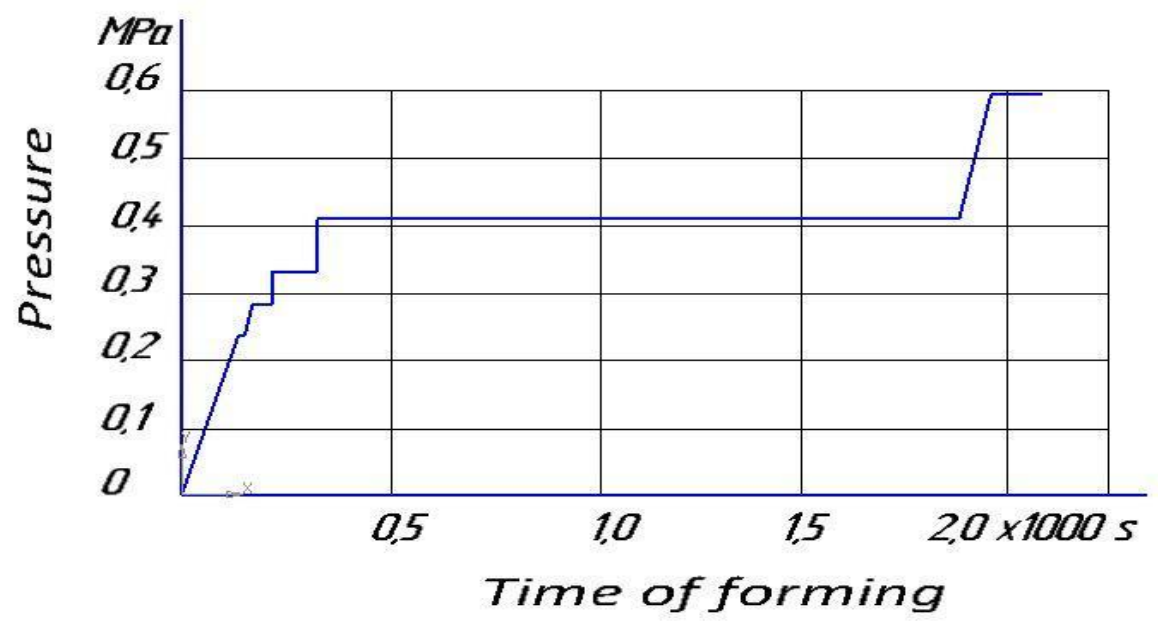

Fig. 5manually, recalculating the processing time after time and visually controlling the maximum rate of deformation. 
It should be noted that at relatively lower optimum temperatures, the stress in the superplastic flow is higher, all other conditions being equal. When the central part of the billet is cooled, the intensity of the superplastic flow becomes lower there and increases in the peripheral areas. It is assumed that due to this effect, the thinning in the central part will be less and the thickness of the final part will decrease, which will have a positive effect on the final quality of the product.

At the initial stage, the new solution procedure and the "manually" obtained pressure diagram were compared under isothermal conditions with the process obtained from the previous calculation (with the built-in pressure control algorithm). The pressure diagrams are shown in Figure 6. When creating the pressure diagram manually, the processing time was reduced from 1926 seconds to 1327 seconds compared to the results for the built-in algorithm. The pole sinking was $63 \%$ for both the thermo mechanical analysis procedure and the CREEP procedure, which indicates a similar calculation procedure and a proper approach to plotting the pressure diagram manually.

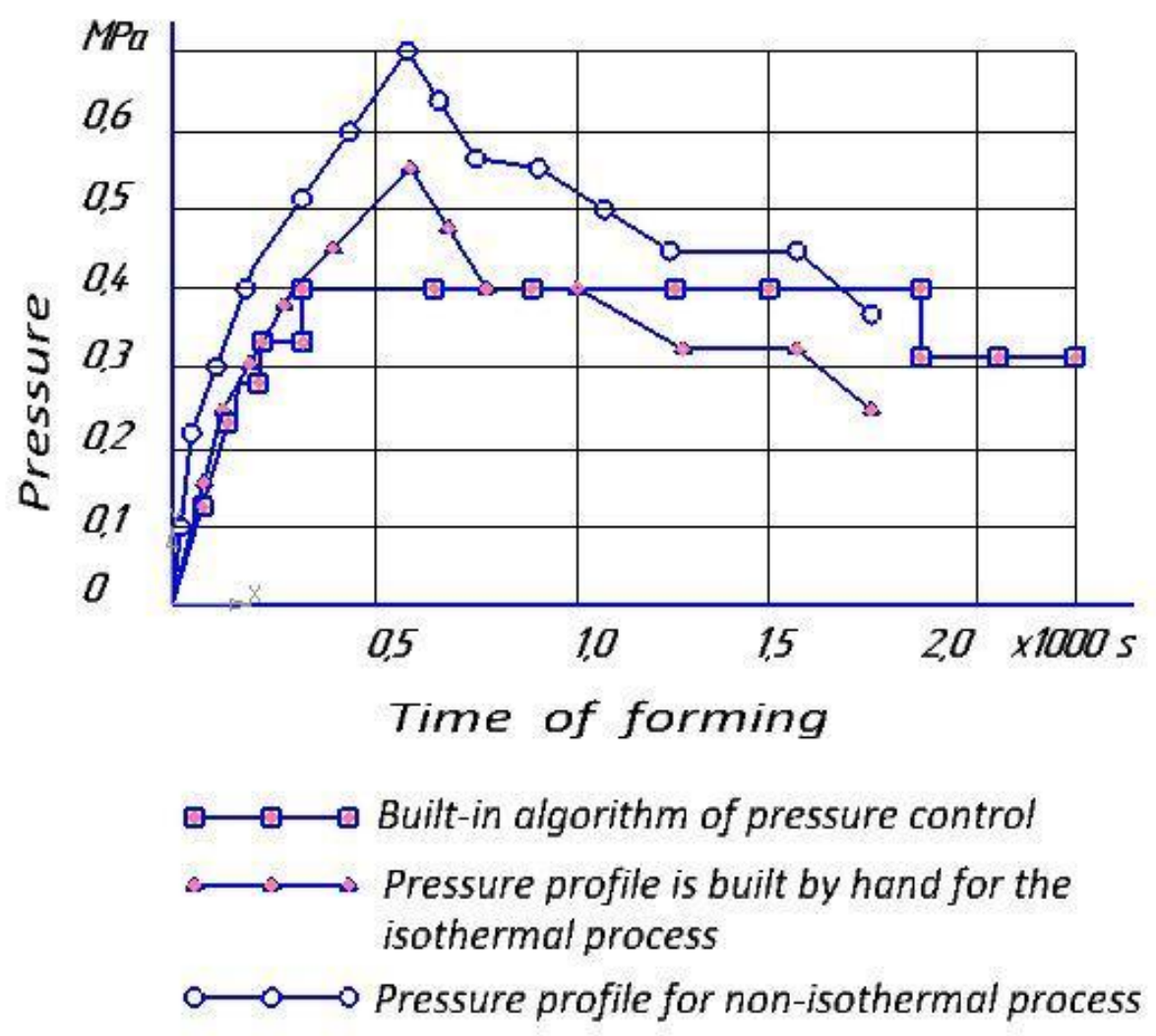

Fig. 6. Pressure diagrams.

The analysis of the obtained results makes it possible to predict the possibility of calculating the technology of gas-forming and pressure bonding in the solid phase for manufacturing torus billets from superplastic titanium alloys with an outer diameter up to $1500 \mathrm{~mm}$ and wall thickness up to $8 \mathrm{~mm}$ and diameter in cross-section up to $400 \mathrm{~mm}$. The possibilities are determined by the availability of appropriate equipment and technological equipment. Currently, in Russia, equipment for the production of torus bars with an outer diameter up to $1200 \mathrm{~mm}$ is available. 


\section{Conclusion}

A promising technology for the production of pipeline elements and bends with a diameter of $50 \ldots 250 \mathrm{~mm}$ made of titanium alloys by gas-forming under super plasticity conditions combined with a pressure joining in the solid phase is proposed. This makes it possible to reduce the cost of production not only by increasing the productivity of the production process but also through the use of new design and technological solutions.

The potential possibility of modeling super plastic moulding of complex products using shell elements in the SIMULIA Abaqus software package is shown. Comparison of the results of the calculation and experiment shows a satisfactory convergence with a difference of $5-7 \%$.

A model is constructed to estimate the effect of uneven billet heating on the thickness difference and other parameters of the non-isothermal gas forming process. The positive effect of cooling of the central part of the billet on the thickness distribution along the wall of the final product is shown.

The software Abaqus/Standartmakes it possible to calculate the optimal parameters of the gas-forming process necessary for its implementation.

The report study was funded by RFBR, project number 19-38-90152\19.

\section{References}

1. R.R. Mulyukov, R.M.Imaev, A.A. Nazarov, M.F. Imaev et al, Superplasticity of ultrafine-grained alloys: Experiment, theory, technology. (Moscow: Nauka, 2014).

2. A.A. Shitikov, Several aspects of the finite elements modeling of superplastic forming, Proceedings of the Tula State University. Technical science,10-1, 133-138 (2014).

3. G.Y. Li, M.J. Tan,K. M. Liew, Three-dimensional modeling and simulation of superplastic forming. In (eds.), Journal of Materials Processing Technology, 150, 7683 (2004).

4. G.GiulianoSuperplastic Forming of Advanced Metallic Materials: Methods and Applications. (Woodhead Publishing, 2011).

5. D.A. Pereira, M.H.F. Batalha, A.F. Carunchio, H.B. Resende, Analysis of the superplastic forming process applied to the aerospace industry: a case study of all 5083 alloys, Full Paper Aerospace Technology Congress 11-12 October, Solna, Stockholm. New materials and processes (2016).

6. M.A. Nazzal, M.K. Khraisheh, B.M. Darras Finite Element Modeling and Optimization of Superplastic Forming Using Variable Strain Rate Approach, JMEPEG, 13, 691-699 (2004).

7. A.M.Smyslov, V.K. Berdin, N.V. Berdin, V.V. Lukianov, Feature of strain state formation during superplastic forming of multilayered sandwich structure. Vestnik UGATU. 4: 53-60. (2014)

8. S.M. Vaytsehovich, Ya.A. Sobolev, G.G. Krivenko,A.V. Barayev, S.P. Polikarov, Gas Isothermal Forming of Hemispheres for Titanium Spherical Balloons in Vacuum Environment (2013). 